\title{
Moving Average Convergence / Devergerance and Relative Strength Index Applied to Predict Price of ASE
}

\author{
Dr. Mohammad Alalaya \\ Dr. Hani, A, Alrawshdeh \\ Dr. Akram Alawad \\ Associate professor \\ Quantitative methods of economics \\ Al-Hussein Bin Talal University \\ Ma'an, Jordan
}

\begin{abstract}
Technical analysis of the stock market is a procedure to forecast the future evolution of stock prices, taking into account the past and including a multitude of highly Varied techniques, therefore the MAC, and RSI, which is of the group of technical tools and used widely as a best technical indicators, in this paper we are taking account of trading volume and the prices, we applied the closer forms of the indicators. The specialized investigation tools or indicators such as MACD, EMA, RSI which are valuable to achieve with preceding development of computerized procedures, which can be utilized of Neural Network, and supper vector machine and other methods, enhanced we can use the algorithm approach to have precise results.
\end{abstract}

Keyword: Neural Network (EMA) Exponential moving Average (MACD) Moving Average convergence divergence. (RSI)Relative strength index, Technical indicators

\section{Jell classification: F 31, G 13}

\section{Section one}

\section{Introduction}

\section{1-1 : Hypothesis of the study}

Hypothesis 1: The application of the MACD and EMA indicators, RSI significantly contribute to the strategy of optimization results of trading assets on the financial market.

Hypothesis 2: The MACD and indicators are adequate for monitoring and assessments of the stock market price through the basic assumptions of technical analysis, which are:

The market discounts all relevant information's of prices of the stock market are moves always in trend, and the history of movements of prices are tending to repeat it.

\section{1-2 : previous studies}

While technical analysis focuses in there research and studies mainly on price and returns of the company's stock, others studied a company's underlying indicators of profit. Some others advise to analysis and examine psychological aspects of demand of company's stock and the factors, which are, affected it. While the fundamental analysis are occupied and are integrated into these affairs, other technicians are employed to use and try many techniques seeks to exploit patterns of prices and trends in the financial market, which aims to forecast stock price movements to formulate their decisions in selling and buying stocks in financial markets tools to ensure of their profitability. Many authors are employed of earnings dividends, and R \& technique, such as (Lo et. al, 2000), (Chen et. al, 2000) and (Rou Wnhorst, 1998). Results of their papers indicate that beat the market in risk of natural returns. (Gunasekarage and Power, 2000), they said that the used of technical methods that employed can generate an excess returns to investors, they have studied south Asian markets while (Retz, 2006) in this study shows the expectation of investors self - fulfilling and their behavior can confirm the profitability also can conduct the sensible explanation of which rule in financial market actually works. 
(Fong and Youn, 2005), they concentrate on historical data analysis, and explain momentum as an upward trend in a time series, but they are not given an explanation of the underlying processes which they are used in their study. The study of the stock market reveals an entirely different force at day trading, and the price of stock really has strong evidence to sales and profits to the traditional models, rather than the gaps of prices, and the changes of investors demand which is not affected directly with a company's competitive success in trading an financial markets.

The economists and technical analysis are not paying full falling attention to the forces which affect the financial market such as supply and demand, rather than interested in the participation of price support and resistance for individual stocks. The efficient market hypothesis says that the stock price of assets reflects all known information about the asset; therefore the lonely new information can cause the changes in asset price in the stock market.

Technical analysis, in general, used the historical data (Past data), mainly the volume information and old data prices, -10 predicated the future market prices movement and quantities techniques to derive the answers for questions appears in financial markets as risk management and credit analysis, hedging, derivatives price, portfolio optimization.

(Micko Tanaka et. al, 2007), studied the adaptive use of technical indicators on the tick data of various stock prices for the prediction of intraday stock prices on the New York stock exchange. Where (Chong and Ng, 2008), they studied two years data of the London stock exchanges FT 30 index, they examined the profitability of the MACD and RSI, they have found that in most cases they have studied RSI and MACD rules can generate returns higher than other strategies such as buy \& hold strategy. (Z.K, Silagadze, 2011) he used a new indicator for technical analysis tools for knowing the market movement of share price, this indicator is moving Minimax to identify lines of resistance and supports the support line happens when the prices crosses a moving average after the local minimum admit indicates to the price which a majority of trader feels that prices will move higher is the problem is fluctuations of the prices.

(Treynor and Ferguson, 1970) argued that when the non-public information is considered, technical analysis can be produced sizable profits. Jensen and Benton, 1985) argued that past information cannot be used to predict future prices.

Therefore this study is used in the trend charts, and indicators to teach the objective of the study. Moving averages are extremely versatile, they allow you to easily decipher the trend, anticipate a change in trend. Moreover, thereby giving different ways to view related information. The moving average offers perhaps the easiest method for deciphering a market's trend. The most common moving Average is the simple moving average (SMA), which totals the close price over a certain number of periods and then divides, essentially calculating the arithmetic mean.

They are a variety of techniques to predict whether an investment would be portfolio profitable not in a short-run and in the future in long - run. There are many types of technical analysis such momentum and RSI and other types such as MACD, and this paper is an attempt to develop a system that can combine the information of different parameters using the different technical method to predict future. The system was developed and tested for stock companies as sectors' in the Amman stock exchange.

(Nagel and Shaken, 2010) used a cross-sectional method of asset pricing and they have argued that it is misleading and the high cross-sectional $\mathrm{R}^{2}$ and small pricing errors. Dacoragna, M, M. Miller, U, A, Olen R, B. and Piter O.V. (1998).(Modeling short-run volatility with Garch and H arch models financial time series, eds. C. Dunis and B. Zhou New York: Wiley.

The investor preferences are represented in fewer movements as possible, ais rapid and shifting of weights in portfolio, clear and significant weights of assets in the portfolio, the investing process need constant attrition, then exclude erratic changes in the portfolio, and the psychology must not enter in investing process. While many authors report strong support for a time series model of daily volatility allows long-term returns, that is, trends to affect volatility levels, such as (Miiller et. al, 1997) and (Dacorgna et. al, 1998). (Li and Chong, ) use the human trader experiment approach to compare the performance of experienced and novice traders. This paper organized as section one is an introduction, section two literature review, section three data and empirical results, where section four is the conclusion. Then references of paper. 


\section{Section Two}

\section{Review Literature:}

\section{2 : Identification of EMA, MACD,RSI:}

To identify lines of resistance and support which declare below in figure (1), if the prices of shares goes through the local maximum and crosses among average if the resistance line indicating the price at which a majority of traders expect that the price moves lower the support line drive up when the prices among average after the local minimum, this means that the support line indicates that price at which a majority of traders feel that prices move higher, the problem is the fluctuations of prices which hampers the identification of the local extremism this can be demonstrated in figure (1).

\section{Figure (1): The resistance and support of prices in the stock market}

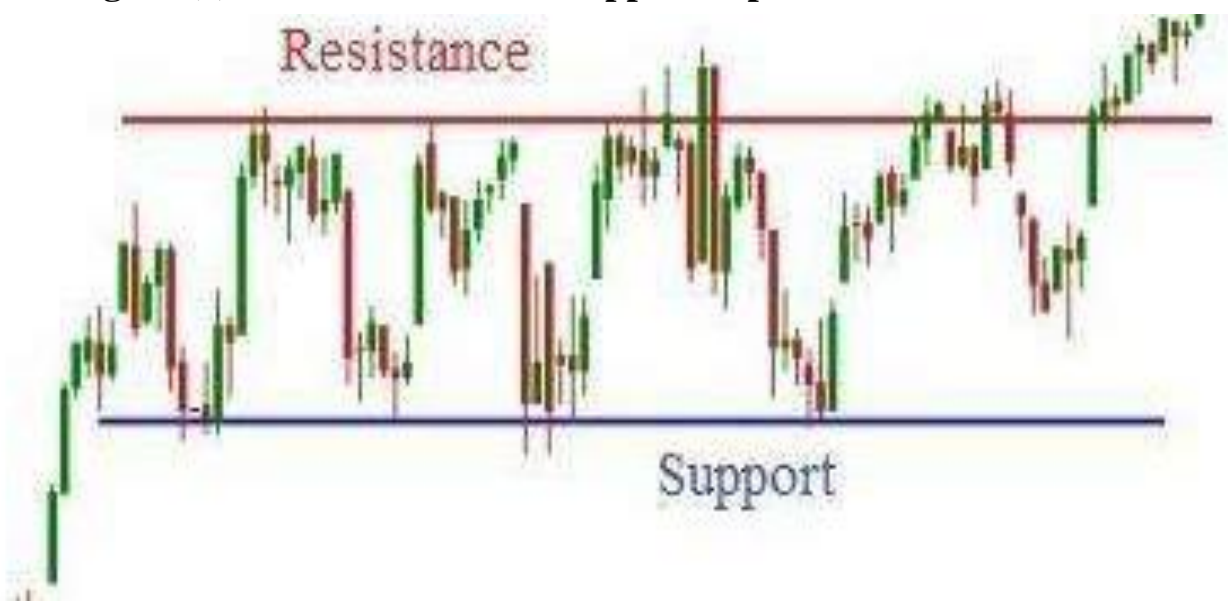

The resistance level is a value point on the outline where brokers expect most extreme supply (for selling)for the stock/list. The resistance level is constantly over the present market price where the resistance is one of the basic specialized investigation devices which showcase members take a gander at in a rising business sector. The help level is dependably below the current market price. There is a most extreme probability that the cost could fall until the support consolidates, ingest all the request, and afterward begin to climb bearing( Aparna Bhatt and Sowmya Kamath, 2011).

(Neftci, 1991) in his paper showed a few rules which can be used as a tool for technical analysis, but even welldefined rules were shown to be useless in prediction, this can happen when the process is non-linear. In his paper he said that rules might capture some information, test proves that technical analysis tools as a case for the moving average rule.

Data predicating of stock prices, which always faced the fluctuations of stock prices which daily increase or decrease.

Figure (2): MACD signals fluctuation of daily prices

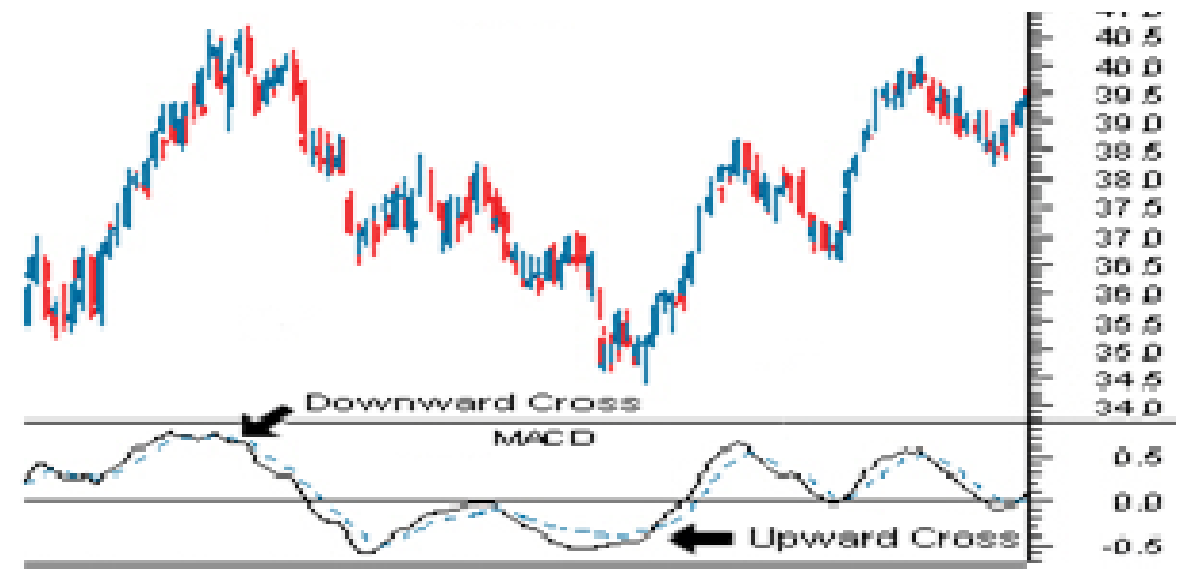


When the MACD is positive, it signals that the shorter term moving average is above the longer term moving average and suggests upward momentum. The opposite holds true when the MACD is negative - this signals that the shorter term is below the longer and suggest downward momentum. When the MACD line crosses over the centerline, it signals a crossing in the moving averages. The proposed system which is performed as framework of this paper to research the trend prices, mainly it predict the future trend of stock market and the fluctuation of stock prices we can be utilized of input layer (structure of the natural network, this can be an input layer and the hidden layer, we can be introduced MACD to the model as in figure (2).

\section{Figure (3): Hidden Markov Model}

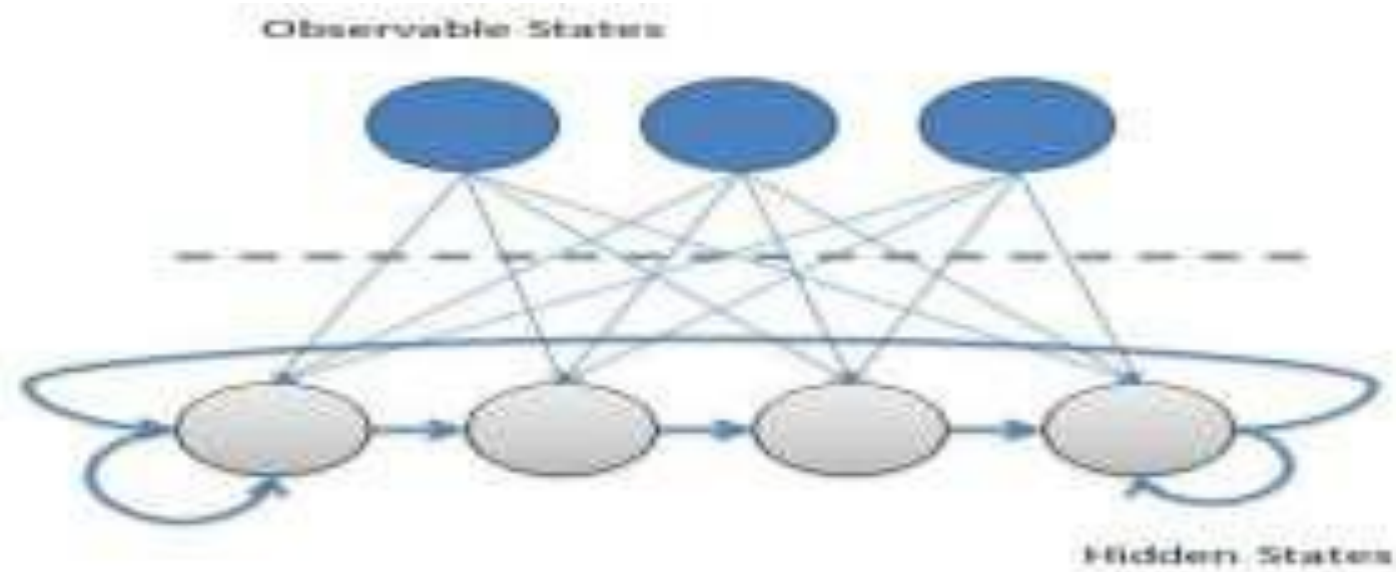

In this model we can use the algorithm, then we can use back propagations algorithm to adjust the weights and bias of network by, repeating training. This can be figured in the below figure (4).

\section{Figure (4): Artificial network can be used in technical analysis}

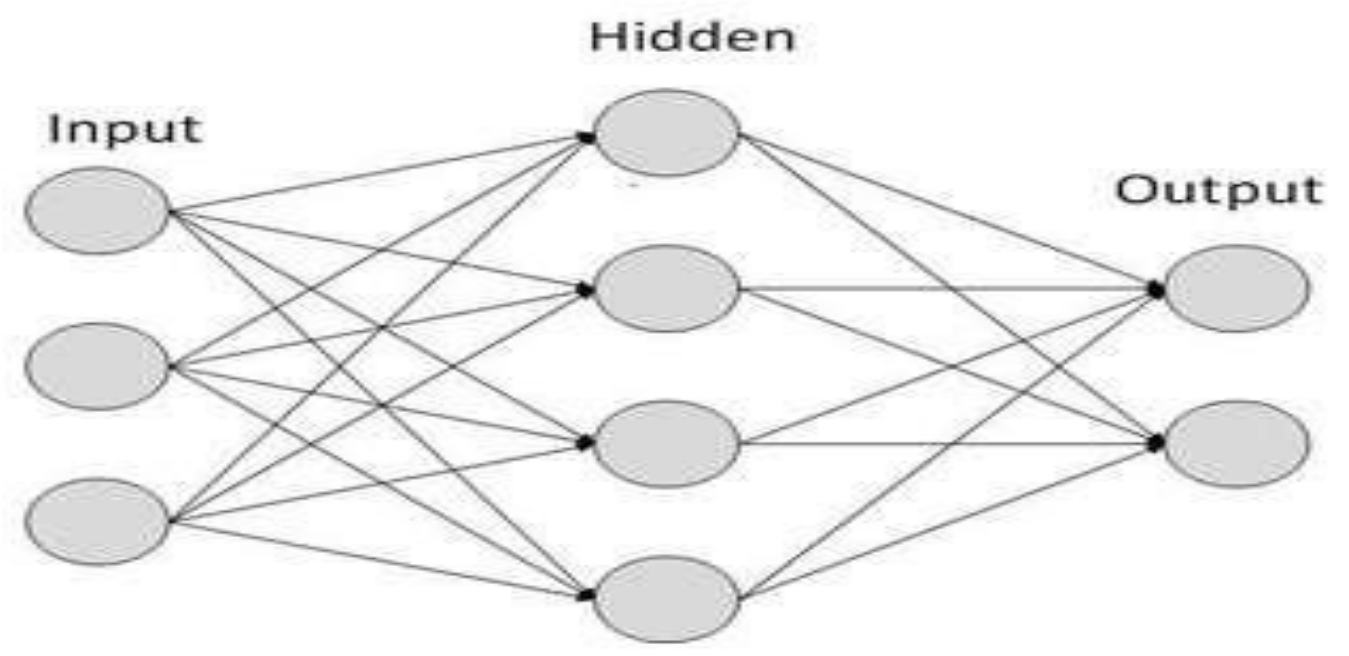

favorable circumstances yet a standout amongst the most perceived of these is the way that it can really gain from watching informational collections. Along these lines, Artificial Neural Network is referred to for as an irregular capacity estimation device, These layers are associated with each other. The main layer comprises information neurons. Those neurons send information on to the second layer, which thusly sends the yield neurons to the third layer. Preparing a counterfeit neural system includes looking over permitted models for which there are a few related calculations. connected the Neural Networks with a various number of shrouded layers to examine the expectation of the Stock costs. Khan et al. Due to the obtained results, when the sum of squares of network output layers is less than a specified sum of squares. We can save the weights and bias of the network. In general, the stock market reflects the fluctuation of the market economy in another hand the stock market is characterized by high - risk, high - yield so the investors are concerned about the analysis of stock market. 


\section{2-2 : The models equations :}

The determination of EMA requires the calculation of a simple arithmetic average SMA of the data of first $\mathrm{n}$ days the formula for calculation depends on the following:

$$
\mathrm{SMA}_{\mathrm{N}}=\frac{\mathrm{X}_{1}+\mathrm{X}_{2}+\ldots \ldots \ldots+\mathrm{X}_{\mathrm{N}}}{\mathrm{N}}
$$

where $\mathrm{X}_{\mathrm{N}}$ : represent the value corresponding to $\mathrm{N}$ days from data starting, and the $\mathrm{SMA}_{\mathrm{N}}$ is the arithmetic average of a string of data corresponding. We can write the exponential moving average of closing prices as:

$\mathrm{EMA}_{\mathbf{N}+1}=\mathrm{a} * \mathrm{X}_{\mathrm{N}-1}+(1-\mathrm{a}) * \mathrm{SMA}_{\mathbf{N}}$

We can compute the EMA as the following equation:

$\left.\mathrm{EMA}_{\mathrm{t}}(\mathrm{N})=\mid \frac{2}{\mathrm{~N}} * \mathrm{Pi}-\mathrm{EMA}_{\mathrm{t}-1}(\mathrm{~N})\right]+\mathrm{EMA}_{\mathrm{t}-1(\mathrm{~N})}$

a buy signal is produced when MACD crosses Zero from below, while a sell signal is obtained when MACD crosses Zero from above. To compute $\mathrm{i}_{\mathrm{t}}(\mathrm{N})$

$$
\operatorname{RSi}_{\mathrm{t}}(\mathrm{N})=\mid \frac{\sum_{\mathrm{i}=0}^{\mathrm{N}-1}\left(\mathrm{P}_{\mathrm{t}-1}-\mathrm{P}_{\mathrm{t}-\mathrm{i}-1)\left\{\mathrm{Pt}_{\mathrm{t}}-\mathrm{P} \mathrm{P}-\mathrm{i}-1\right)}\right.}{\sum_{\mathrm{i}=0}^{\mathrm{N}} \mathrm{P}_{\mathrm{t}-1-\mathrm{P} t-\mathrm{i}-1}} * 100
$$

Where:

RSI (N) is the relative strength index at the time I, N is the bandwidth 1(.) is an indicator function.The moving average convergence divergence (MACD) indicator requires there exponential moving average (EMA), which are lagging indicators, to identify the construction or reversal of trend.

$M A C D=\operatorname{EMA}_{1}$ (12-day closing prices) $-\operatorname{EMA}_{2}$ (26 days closing prices)

The second indicator, called signal line the signal line 9 is:

Signal = EMA (9 days MACD)

for the first EMA $\mathrm{t}_{\mathrm{t}}=\frac{\mathrm{CP}_{1}+(1-\mathrm{q}) \mathrm{CP}_{2}+(1-\mathrm{q})^{2} \mathrm{CP}_{3}+\ldots \ldots \ldots+(1-\mathrm{q})^{\mathrm{t}-1} \mathrm{CP}_{\mathrm{t}}}{1+(1-\mathrm{q})+(1-\mathrm{q})^{2}+\ldots \ldots+(1-\mathrm{q})^{\mathrm{t}-1}}$

$\mathrm{CP}_{\mathrm{t}}=$ is the closing price on day $\mathrm{t}$.

Most of the researchers in economic have been sceptical of technical analysis, they argued that any dissemble pattern in time series price data would be exploited, they used the efficient markets hypothesis which still dominate their sense that financial economists have not yet researched a consensus on better motel of pries function where the expectations model made empirical evidence to analysis the market fair prices. Despite the widespread use of technical analysis, still there is an overwhelming skepticism regarding it is used among academic remarking the misconception: Some of the variables of finance are not measurable, while unlike quantitative finance. Also, the charting techniques are difficult to justify theoretically and are normally expressed in Jargons that are alien to academic (Campbell, and Mackinaly, 1997).

Technical analysis has its core postulates, as:

1- The price of the market more with the trend (Murphy, 1999).

2- Market action discounts everything (Murphy, 1999).

3- The history repeats itself (Murphy, 1999).

In this paper we choose MACD which developed by Gerald Apple, this indicator gives signs about the correlation between Two prices moving average hence the moving average between to sample 12 days MACD which faster and reasonable for most movement, while 26 days is slower and less reactive to the price change in the underlying security. 


\section{Section Three}

\section{Data and Empirical Results}

\section{1 -3 :Data for the study:}

In this paper, the study will use the daily closing values of Amman stock exchange April 2013 - to June 2017, and the daily trading volume corresponding to the same period of study, an indicator which utilized for this purpose is MACD and RSI.

\section{Empirical results:}

We apply first step the classic form of RSI, results in the table (1) below.

Table (1): Results of the classic form of the RSI.

\begin{tabular}{|l|l||l|l|l||l|}
\hline $\begin{array}{l}\text { Choice of the } \\
\text { RSI }\end{array}$ & $\begin{array}{l}\text { Total No. of } \\
\text { Signals }\end{array}$ & $\begin{array}{l}\text { The No. of } \\
\text { successful } \\
\text { signal }\end{array}$ & $\begin{array}{l}\text { No. of losing } \\
\text { signal }\end{array}$ & $\begin{array}{l}\text { Cain from } \\
\text { successful signals }\end{array}$ & $\begin{array}{l}\text { Gain } \\
\text { losing signals }\end{array}$ \\
\hline \hline Buy & 21 & 23 & 487.38 & -674.26 \\
\hline \hline Sell & 48 & 23 & 396.13 & -459.81 \\
\hline Total & 53 & $\mathbf{4 6}$ & $\mathbf{8 8 3 . 3 9}$ & $\mathbf{- 1 1 3 4 . 0 7}$ \\
\hline
\end{tabular}

Total gain:

$-\mathbf{1 5 9 . 8 8}$

$-63.68$

Due to results of this table, the sell and buy in ASE of the period of study are: the total loss of 223.68 points, is signed and it can be completely transformed into gain in the case of totally reversing the interpretation of the index that is transforming the buy signals in sale signals and vice versa.

Table (2 ) statistic summary of daily returns of ASE 2013-2017

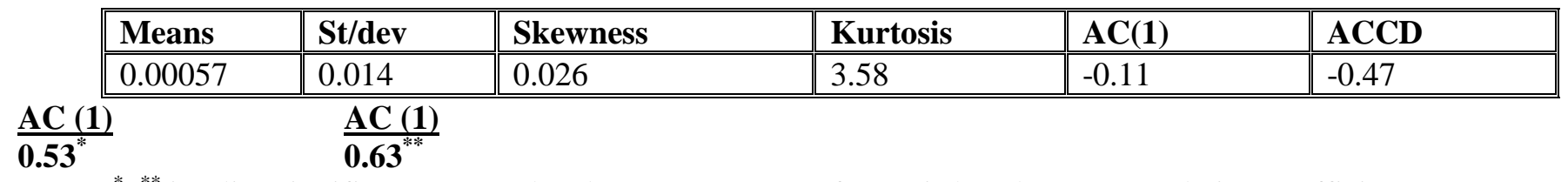

Notes: ${ }^{*},{ }^{*}$ implies significance at $5 \%$ level at 10\% AC (1) refers to i-th order autocorrelation coefficient.

Table ( 3 ): profit/loss and retunes from the signals on the daily movement of ASE

\begin{tabular}{|c|c|c|c|c|c|}
\hline & $\overline{\mathrm{MAC}}$ & Signal line & $\begin{array}{l}\text { Closing price } \\
\end{array}$ & Buy & sell \\
\hline 10-Jan, 213 & -24.72 & -28.34 & 1541.46 & 154.46 & 1541.46 \\
\hline 15, Dec. 2013 & 2.64 & 2.36 & 1608.31 & 1593.42 & 1608.31 \\
\hline 9, Jan. 2014 & -16.54 & -11.93 & 1593.42 & 1873.64 & 1593.4 \\
\hline 21, April. 2014 & 78.29 & 96.30 & 1873.64 & 1837.52 & 1837.52 \\
\hline 30, Jan mber 2015 & -61.13 & 23.18 & 1837.52 & 2169.14 & 2169.14 \\
\hline 30, Dec. 205 & 87.09 & 48.72 & 2169.14 & 2169.14 & 2169.14 \\
\hline 2 2, Jan. 2016 & 93.16 & 57.23 & 2232.20 & 2232.20 & 2232.20 \\
\hline 30, Dec. 2016 & 36.37 & -40.21 & 1817.42 & 1817.42 & 1817.42 \\
\hline 8, Jan. 2017 & 36.87 & 19.67 & 1675.09 & 1675.09 & 1675.09 \\
\hline 30, Dec. 2017 & 91.27 & 83.06 & 1897.21 & 1897.21 & 1897.21 \\
\hline
\end{tabular}

Total profit $\mathbf{1 1 5 6 . 1 8}$

Returns $\quad 64.7291$

Average of returns: $5 \% 1 \quad 9.51 \%$

Signal Buy 18 Sale 18 
Figure (5): draw of MACD and signal to returns from 2o11-2013.

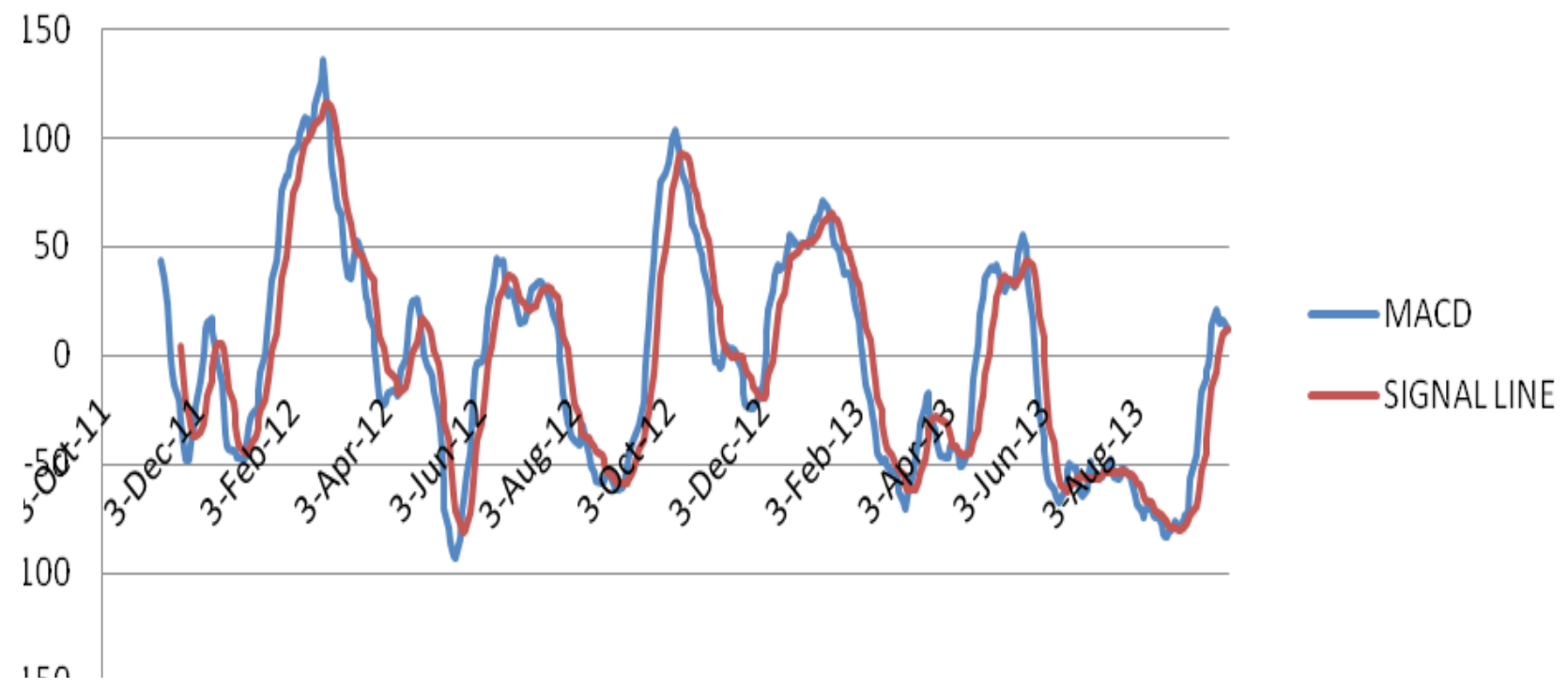

From table (3) and chart, we can interpret that the ASE daily price movement by using the MACD indicator can generate 18 buying signals and 18 signal selling from 1 January 2013 to 30 December 2017 the index has given profit in trading transactions is 1156.18 per share and proving average returns of $9.51 \%$ per trading transaction.

Table (4 ): Results of MACD -4 trading Strategy depends on the base sample

\begin{tabular}{|c|c|c|c|c|c|}
\hline $\begin{array}{l}\text { Types of MACD } \\
\text { rule }\end{array}$ & $\begin{array}{l}\text { Unconditional } \\
\text { daily returns }\end{array}$ & $\begin{array}{l}\begin{array}{l}\text { Number of } \\
\text { buys }\end{array} \\
\end{array}$ & $\begin{array}{l}\text { Number of } \\
\text { Sales }\end{array}$ & $\begin{array}{l}\text { Buy } \\
\text { returns }\end{array}$ & Sell returns \\
\hline MACD-4 & 0.00063 & 78 & 59 & $\begin{array}{l}0.0006 \\
(2.95)\end{array}$ & $\begin{array}{l}-0.00019 \\
(-0.73)\end{array}$ \\
\hline Excess returns & 0.0003 & & & & \\
\hline
\end{tabular}

The result of the table (4) is in slight contrast with the result in the base sample where the predictability of MACD-4 strategy which is better than other strategies of MACD -2, -3 the excess returns are produced by a MACD-4 strategy with 0.0003 percent and unconditional daily returns 0.00063 .

Whereas all result reveals that the moderate mean daily returns buy minus sell returns and mean daily excess. Finally, much moving average convergence divergence (MACD) trading rules can be used as a predictive ability such as MACD-2, MACD-3, MACD-4, in our performance MACD-4, which applied popularly by many scientists.

\section{Section Four}

\section{Conclusion}

Many indicators can be used to forecast and predict the daily buy and sell off (MACD) Be Moving average convergence divergences in comparison of classic form of MACD and (RSI), the relative strength index, and the purpose of this process is to answer the question that the hypothesis from which the fundamental analysis departs is that in daily time, and if that hypothesis which says that prices of stock have a tendency towards their intrinsic value. This paper can be concluded through analysis by analyzing the results of the approach of MACD strategy as a classic from an RSI and the reversed interpretation which gives predictive results for best forms. The MACD has the productive ability in uses of analysis as technical analysis we have used one strategy (MACD-4) which applied to execute that trading signals, the results reveal that the strategy is significance profitable in ASE. As other MACD-1, MACD-2, MACD-3 is when we applied to the data are lower among these results, and some of them we have an evidence that is useless. But MACD-4 reveals fruitful for the interpretation of its results. Notably that the centerline crossover of the RSI to predictive ability in the ASE, in particular, the RSI (17.43) rule perform well in the mean cant central index and this rules can general significance profit. Finally is the recommendation from our finding of analysis that our advice for practitioners and trader to at least ascertain the profitability of these rules and to check and examine the individual shares as an extension insures of dealing trading. 


\section{References}

A. U. Khan et al. (2005) "Stock rate prediction using backpropagation algorithm: Analyzing the prediction accuracy with the different number of hidden layers," Glow gift, Bhopal, 2005.

Alam GM (2011). A further editorial guideline for writing manuscript in the field of social science: A special

Aparna Bhatt, SowmyaKamath S., "Automated Stock Price Prediction and Trading Framework for Nifty intraday trading", IEEE - 31661.

Bodas-Sagi, D. J., Fernández, P., Hidalgo, J. I., Soltero, F. J., Risco-Martín, J. L. (2009) Multi-objective optimization of technical market indicators. In: Proceedings of the $11^{\text {th }}$ Annual Conference on Genetic and Evolutionary Computation. GECCO'09. pp. 1999-2004.

Computation Conference (GECCO'2008). New York2008. pp. 1851-1858.

Dejan Eric, G.A., Srdjan Redzepagic (2009). Application on MACD and RSI indicators as functions of investment strategy optimization on the financial market, Zbornik Radova Ekonomskog Fakulteta u Rijeci, 27, pp. 171-196.

Erence Tai-Leung Chong, S.H.-S.C., Elfreda Nga-Yee Wong (2010). A comparison of Stock Market Efficiency of the BRIC countries, Technology and Investment, 1, pp. 235-238.

Fernández-Blanco, P., Bodas-Sagi, D. J., Soltero, F. J., and Hidalgo, J. I.(2008) Technical market indicators

Grant J, Wolf A, Yu S (2005). Intraday price reversals in the US stock index futures market: a 15-year study. J. Bank Financ., 29(5): 1311-1327.

Lui, K.M.; Chong, T.T.-L. Do technical analysts outperform novice traders: Experimental evidence. Econ. Bull. 2013, 33, 3080-3087.

Neftçi, S.N. Naïve trading rules in financial markets and Wiener-Kolmogorov prediction theory: A study of "technical analysis". J. Bus. 1991, 64, 549-571.

$\mathrm{Ni}, \mathrm{H}$;; Yin, H. Exchange rate prediction using hybrid neural networks and trading indicators. Neurocomputing 2009, 72, 2815-2823.

optimization using evolutionary algorithms. In: Keijzer (Ed.) Proceedings of the Genetic and evolutionary

perspective for African Journal of Business Management (AJBM). Afr. J. Bus. Manage., 5(1): Editorial.

R., Rosillo, D.D.L.F., J.A.L. Brugos (2013). Technical analysis and the Spanish stock exchange: testing the RSI, MACD, Momentum and stochastic rules using Spanish market companies, Applied Economics, 42, pp. 1541-1550.

Sinohydro Press, 2003 [3] Huadong Qin. Based on neural network forecasting stock market trends. Chinese dissertation database, 2005 [4] Zhijun Peng. Some new data mining method and its application in the Chinese securities market. Chinese dissertation database, 2005.

Stawicki, S.P. Application of financial analysis techniques to vital sign data: A novel method of trend interpretation in the intensive care unit. OPUS12 Sci. 2007, 1, 14-16.

Stock data analysis based on BP neural network 2010 second international Conference on communication software and network [2] Fengjing Shao, Zhong Qing Yu. Principle and algorithm of data mining.

Timmermann A, Granger C (2004). Efficient market hypothesis and forecasting. Int. J. Forecast., 20(1): 15-27.

Ülkü, N. and E. Prodan (2013). Drivers of technical trend-following rules' profitability in world stock markets, International Review of Financial Analysis, 30, pp. 214-229.

White, R. Technical Analysis Indicator That Works Turns Positive For These Stocks, Forbes, 15 April 2013. Available online: http://www.forbes.com/sites/greatspeculations/2013/04/15/technical-analysis-indicatorthat-works-turns-positive-for-these-stocks/ (accessed on 27 December 2013).

Yu, H., G.V., Nartea, C., Gan and L.J., Yao (2013). Predictive ability and profitability of simple technical trading rules: recent evidence from Southeast Asian stock markets, International Review of Economics \& Finance, 25 , pp. 356-371.

Yu-Feng Lin, Chien-Feng Huang, Vincent S. Tseng, "A Novel Methodology for Stock Investment using Episode Mining and Technical Indicators", 2012 Conference on Technologies and Applications of Artificial Intelligence. 